\title{
16 Possession and ownership of data
}

Who is the data possessor, the data owner and the dat a processor in the context of the data processing described?

How do these terms exactly differentiate themselves from each other?

\section{1 "Dateneigentum"/"data ownership"}

The German term "Dateneigentum" ("data ownership") does not exist in legal jargon. In Germany the term for property ("Eigentum") always refers to "corporeal objects" (cf. $\mathbb{5} 590,903 \mathrm{BCB})$. Data and information do not belong to these objects. For the described scenario it follows that there is no data ownership (in the sense of "Dateneigentum"). Rather, the classification and protection of intangible assets in the form of data and information is governed by intellectual property law (including copyright law and patent law).

\subsubsection{Copyright and Copyright related rights}

The German copyright law protects authors of works, that are the author's own intellectual creations ( $\$ 2 f f$. UrhG), in their intellectual and personal relationships to the work and in respect of the use of the work ( $\$ 11$ UrhG). Protected works could be literary works, such as written works and computer 
programs ( $\$ 2[1]$ Nr. 1 UrhG), illustrations of a scientific or technical nature ( $\$ 2[7]$ UrhG) or collections and database works ( $\$ 4$ UrhG).

Databases are additionally protected by a "related right" ("Verwandtes Schutzrecht"). According to $\$ 87 \mathrm{~b}$ UrhG the producer of a database has the exclusive right to reproduce and distribute the database as a whole or a qualitatively or quantitatively substantial part of the database and to make this available to the public.

Data of the participants of studies (for example name and address) and pseudonyms are no intellectual creations pursuant to $\mathbb{2} 2 \mathrm{ff}$. UrhG. Furthermore, the data as such is no database (cf. $\$ 87 a$ UrhG).

The copyright protection of the consent form and of the quality reports depends on the human influence on the creation of the respective text or visualisation. In order to fall within the scope of protection of copyright, the the consent form and the quality report must be sufficiently original and individual.

\subsubsection{Patent law}

Legal protection by patent law requires an invention in a field of technology (cf. $\mathbb{\$}[1]$ PatG). Programms for computers and presentations of information are excluded from patentability to the extent to which protection is being sought for the subject-matter or activities referred to as such ( $\$ 1$ [3], [4] PatG). The Patentability of computer-implemented inventions is highly controversial.

\subsubsection{Data protection law}

The General Data Protection Regulation uses the term "own" in the context of a natural person's "own" data (recital 7: "Natural persons should have control of their own personal data"; cf. recital 68: "To further strengthen the control over his or her own data, [...] the data subject should ...”). The information about the participants of the studies (i.a. name and address) are personal data (cf. Art. 4 [1] GDPR).

\section{2 "Datenhalter"/“data holder"/“data possessor"}

The terms "data holder" and "data possessor" are used neither in intellectual property law nor in European data protection law.

\section{3 "Datenverarbeiter"/"data processor"}

The General Data Protection Regulation defines the terms "processing" (= Verarbeitung) in Art. 4 (2) GDPR and "processor" (= Auftragsverarbeiter) in 
Part II of the legal opinions: Detailed Questions on organisational and technical measures

Art. 4 (8) GDPR. For the purposes of the GDPR 'processing' means any operation or set of operations which is performed on personal data or on sets of personal data, whether or not by automated means, such as collection, recording, organisation, structuring, storage, adaptation or alteration, retrieval, consultation, use, disclosure by transmission, dissemination or otherwise making available, alignment or combination, restriction, erasure or destruction. "Processor" means a natural or legal person, public authority, agency or other body which processes personal data on behalf of the controller (Art. 4 [8] GDPR).

The "processor" (Art. 4 [8] GDPR differs from the "controller" [= Verantwortlicher]). For the purpose of the General Data Protection Regulation "controller" means the natural or legal person, public authority, agency or other body which, alone or jointly with others, determines the purposes and means of the processing of personal data. 